\title{
UK doctors under the microscope
}

I t's been billed as the most significant change in the regulation of physicians in the United Kingdom since the General Medical Council (GMC) was created in 1858 and is believed by many to be an indicator of the end of self-regulation.

After years of piloting and squabbling, the UK's new "revalidation" scheme took effect Dec. 3 as part of a bid to elevate the quality of care provided to residents of England, Scotland, Wales and Northern Ireland.

The initiative will compel all of the UK's 230000 general practitioners (GPs) and specialists to be examined once every five years to determine compliance with the GMC's Good Medical Practice ethical guidance, which sets out 12 key attributes of being a good doctor, such as keeping skills up to date, being polite, putting patients first, being honest and trustworthy, and disclosing how their own health may impact their practice (www.gmc-uk.org/static/documents /content/GMP_0910.pdf).

It will also theoretically include an assessment of some measure of competence, as the guidance identifies the provision of "good clinical care" as an indicator of good practice, noting good clinical care includes "(a) adequately assessing the patient's conditions, taking account of the history (including the symptoms, and psychological and social factors), the patient's views, and where necessary examining the patient (b) providing or arranging advice, investigations or treatment where necessary [and] (c) referring a patient to another practitioner, when this is in the patient's best interests."

Doctors in England, though, managed to wring a last-minute concession out of the government late this fall, when they extracted a pledge from the National Health Service (NHS) Commissioning Board (which was established to oversee daily operations in Prime Minister David Cameron's restructured national health system) to fund remediation for physicians who are unfit to practice.

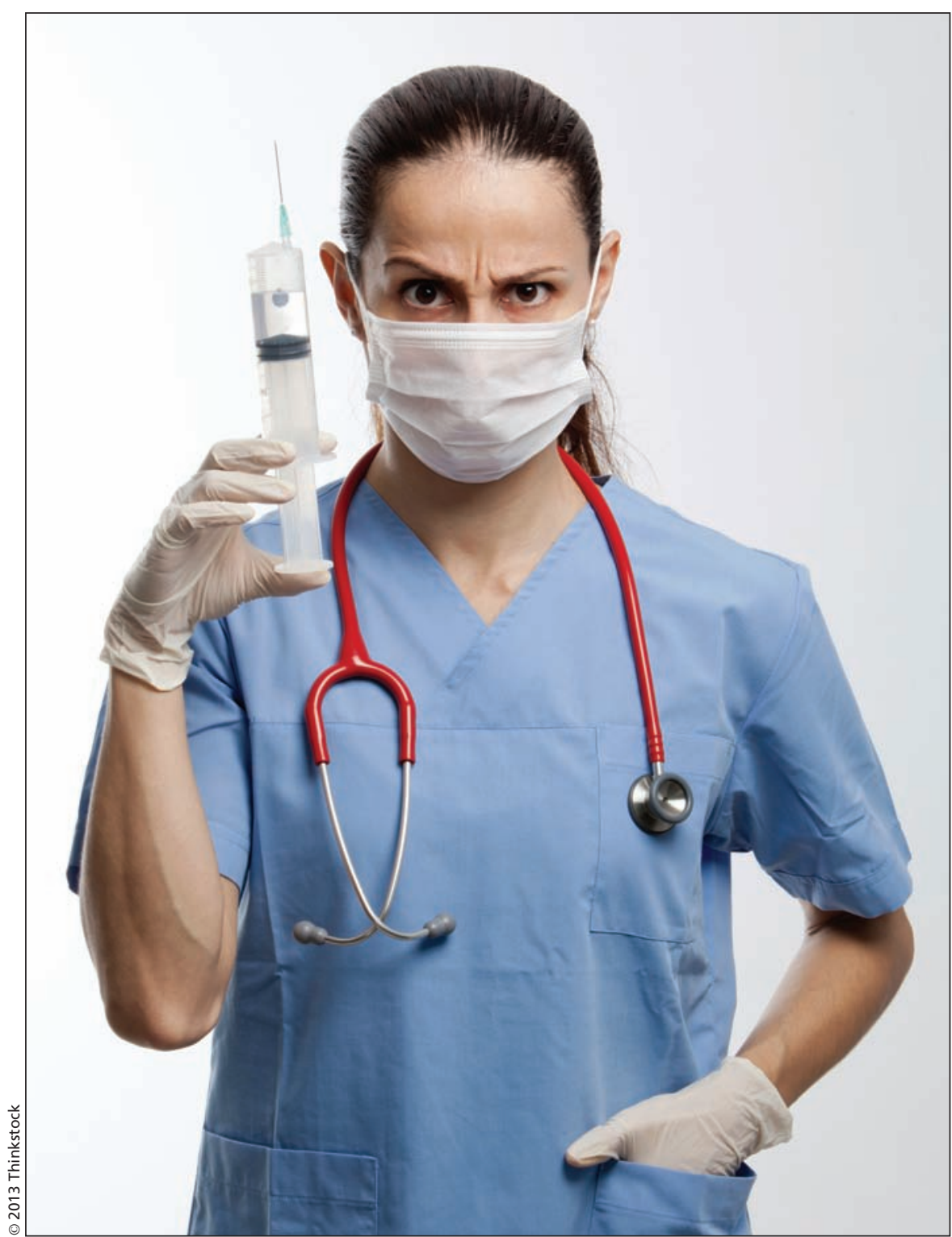

It's estimated that an "extra 1\%" of doctors will need remedial training as a result of the United Kingdom's new revalidation and relicensing initiative.

The concession was welcome, argues Dr. Mark Porter, chair of the British Medical Association. There was an onus on the government to ensure that revalidation wasn't overly burdensome on either physicians or facilities, he says. "The government bears a responsibility for mitigating the direct financial effect that could destabilize GP practices because they happen to contain a GP who is judged to need directed continuing education and professional development."

Revalidation represents a "huge operational and cultural change" for the medical profession and must be a process that evolves, incrementally and pragmatically, through time, says Professor Sir Peter Rubin, chair of the GMC. "Inevitably, there will be some teething problems. ... But we want to learn as we go along. I think that revali- 
dation five or ten years from now will look different from what it is now.'

The notion of revalidation every five years was first proposed in the late 1990s by Dr. Sir Donald Irvine, former president of the council, in the aftermath of the Bristol Royal Infirmary scandal, in which secrecy about the performance of doctors and a lax approach to safety were found to be at the root of high death rates among babies who'd undergone cardiac surgery.

The scheme was delayed in 2004 following Dame Janet Smith's inquiry into the actions of serial killer Harold Shipman, a former Manchester GP who was convicted of murdering 15 patients by administering fatal doses of diamorphine. Smith's findings indicated revalidation plans, as then envisioned, would not have identified dangerous doctors, which led, in turn, to multiyear negotiations over what manner of revalidation might do so.

Under the new arrangement, doctors will be assessed by what is called a "responsible officer," an employee of the NHS or other employing organization (whether pharmaceutical company, government department or military). In aid of that review, physicians will be "required to demonstrate that they are working in a way that meets the values and principles" set out in the guidance. "The evidence that doctors will bring to support revalidation will include participation in a process of annual appraisal, feedback from patients and colleagues, evidence of continuing professional development, reviews of complaints and information about clinical outcomes, where appropriate," according to a Department of Health cost-benefit analysis of the revalidation initiative (https://www.wp.dh.gov.uk/publications /files/2012/11/Medical-revalidation-cost -benefit-analysis.pdf).

"The intention of revalidation is not to catch murderers," Rubin says. "That is not what the GMC does, that is what the police do. The purpose of revalidation is to confirm that doctors are up to date and fit to practise, which indeed the vast majority of doctors are."

Rubin, along with the chief medical officers of England, Scotland, Wales and Ireland, have agreed to be among the first doctors to undergo revalidation. Next in line are more than 700 "responsible officers," followed by the rest of the physician pool, about $20 \%$ between April 2013 to March 2014, and 40\% in each of the following two years.

Through time, revalidation should help to elevate the proficiency of UK physicians, says Dr. Brian Keighley, chair of the BMA's Scottish Council and of a BMA working group on revalidation. "It is easier to help a doctor recognise areas of under-performance at years one and two, than at years 10 and 11. It encourages doctors into reflective practice so that it aids their process of professional development and self-awareness. A very small side effect might be that someone who should not be practising is picked up."

The NHS Revalidation Support Team projects that an "extra 1\%" of doctors will need remedial training as a result of revalidation. England's Department of Health projected that revalidation will cost $£ 97$ million annually. That includes the costs of training responsible officers, paying them to conduct appraisals and obtaining feedback from patients and colleagues. Remedial training is projected to cost $£ 7.8$ million annually.

But the Department of Health contended benefits will outweigh costs over time because identifying poor performers early will result in fewer costly suspensions and a $0.75 \%$ reduction in patient deaths or severe and moderate harm. It also estimated revalidation will reduce litigation costs by $3 \%$ annually, which would not be insubstantial given that NHS Litigation Authority data indicate that payouts for medical miscues more than doubled to $£ 860 \mathrm{~m}$ in 2011 from $£ 400 \mathrm{~m}$ in 2003. - Mike Foster, London, England

CMAJ 2013. DOI:10.1503/cmaj.109-4362 